\title{
Tricuspid valvular dynamics and 3-dimensional geometry in awake and anesthetized sheep
}

Tomasz Jazwiec, MD, ${ }^{\mathrm{a}, \mathrm{b}}$ Marcin Malinowski, MD, ${ }^{\mathrm{a}, \mathrm{c}}$ Alastair G. Proudfoot, MD, ${ }^{\mathrm{a}}$ Lenora Eberhart, BS, ${ }^{\mathrm{d}}$ David Langholz, MD, ${ }^{\mathrm{d}}$ Hans Schubert, BS, ${ }^{\mathrm{a}}$ Jeremy Wodarek, BS, ${ }^{\mathrm{a}}$ and Tomasz A. Timek, MD, PhD ${ }^{\mathrm{a}}$

\section{ABSTRACT}

Objectives: Clinical and experimental tricuspid valve physiology data are derived predominantly from anesthetized subjects, but normal tricuspid valve geometry and dynamics may be altered by general anesthesia and mechanical ventilation. We set out to investigate 3-dimensional geometry and dynamics of the tricuspid valve complex in awake and anesthetized sheep.

Methods: While on cardiopulmonary bypass and with the heart beating, 6 adult sheep $(50 \pm 8 \mathrm{~kg}$ ) underwent implantation of 6 sonomicrometry crystals around the tricuspid annulus. One crystal was implanted on the anterior, posterior, and septal papillary muscle tips, 4 on the right ventricular free wall and 1 on its apex. Pressure transducers were placed in both ventricles. Sonomicrometry and pressure transducer cables were externalized to subcutaneous buttons. After 7 days of recovery, hemodynamic and sonomicrometry data were recorded with animals awake and anesthetized.

Results: Hemodynamic parameters did not differ between groups. Tricuspid annular area contraction decreased with anesthesia $(16.4 \% \pm 4.2 \%$ vs $11.2 \% \pm 3.2 \%, P=.047)$ as did tricuspid annular perimeter contraction $(8.1 \% \pm 2.2 \%$ vs $5.4 \% \pm 1.7 \%, P=.050)$, predominantly due to reduced contraction of the septal annulus $(10.5 \% \pm 2.9 \%$ vs $7.5 \% \pm 3.5 \%, P=.019)$. Tricuspid annular height did not differ between groups. Minimal distance from anterior, posterior, and septal papillary muscle tips to the annular plane did not change with anesthesia. Regional right ventricle free wall contraction was depressed under anesthesia in anterior $(16.3 \% \pm 3.1 \%$ vs $12.3 \% \pm 2.2 \%$, $P=.027)$ and lateral $(14.9 \% \pm 1.3 \%$ vs $11.5 \% \pm 2.8 \%, P=.016)$ segments, whereas the posterior remained unchanged.

Conclusions: General anesthesia did not alter tricuspid annular or subvalvular 3-dimensional geometry but reduced right ventricular contraction and tricuspid annular dynamics. (J Thorac Cardiovasc Surg 2018;156:1503-11)

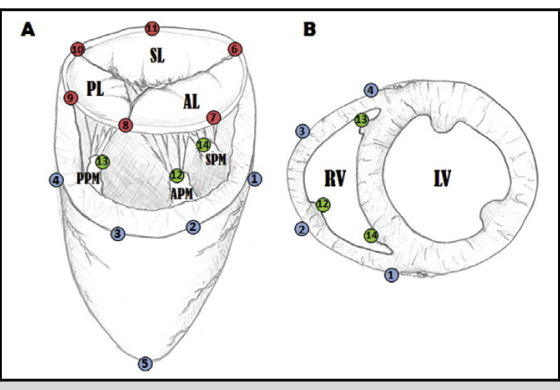

Location of sonometric crystals on the tricuspid valve complex and RV.

\section{Central Message}

The TA in awake animals demonstrates dynamic motion and complex 3D geometry. General anesthesia did not affect valvular geometry but reduced tricuspid annular dynamics.

\section{Perspective}

Dynamic behavior and 3D geometry of the tricuspid complex may differ in awake and anesthetized animals. Current data offer unique insight into tricuspid annular physiology in awake, ambulatory animals and provide context for interpretation of tricuspid dynamics and geometry under general anesthesia during intraoperative decision-making.

See Editorial Commentary page 1512.

\footnotetext{
From the Divisions of a Cardiothoracic Surgery and ${ }^{\mathrm{d} C}$ Cardiovascular Medicine, Spectrum Health, Grand Rapids, Mich; ' Department of Cardiac, Vascular and Endovascular Surgery and Transplantology, Medical University of Silesia in Katowice, Silesian Centre for Heart Diseases, Zabrze, Poland; and ${ }^{\mathrm{c}}$ Department of Cardiac Surgery, Medical University of Silesia, School of Medicine in Katowice, Katowice, Poland.

This study was supported by an internal grant from the Meijer Heart and Vascular Institute at Spectrum Health.

Read at the American Association for Thoracic Surgery Mitral Conclave, April 2728, 2017, New York, New York.

Received for publication Feb 13, 2018; revisions received April 4, 2018; accepted for publication April 13, 2018; available ahead of print May 24, 2018.

Address for reprints: Tomasz A. Timek, MD, PhD, Division of Cardiothoracic Surgery, Michigan State University College of Human Medicine, 100 Michigan Ave NE, Grand Rapids, MI 49503 (E-mail: tomasz.timek@spectrumhealth.org). $0022-5223 / \$ 36.00$

Copyright (c) 2018 by The American Association for Thoracic Surgery https://doi.org/10.1016/j.jtcvs.2018.04.065
}

The tricuspid valve is a complex 3-dimensional (3D) structure that requires fine coordination of its separate components to achieve timely and efficient valve closure. Functional tricuspid regurgitation is increasingly recognized as an important clinical entity, ${ }^{1}$ with growing emphasis on more aggressive therapy with reductive annuloplasty. ${ }^{2}$ Surgical results of annular reduction are still suboptimal, ${ }^{3,4}$ and our knowledge of the precise 3D geometry

- Scanning this $\mathrm{QR}$ code will take you to a supplemental video for the article.

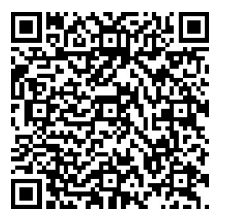




Abbreviations and Acronyms
$\begin{array}{ll}\text { ECG } & =\text { electrocardiogram } \\ \text { ED } & =\text { end-diastole } \\ \text { ES } & =\text { end-systole } \\ \text { IV } & =\text { intravenously } \\ \text { LV } & =\text { left ventricle } \\ \text { PEEP } & =\text { positive end-expiratory pressure } \\ \text { RV } & =\text { right ventricle } \\ \text { TA } & =\text { tricuspid annulus } \\ \text { 3D } & =3 \text {-dimensional } \\ \text { RV-FAC } & =\text { right ventricle fractional area change } \\ \text { RV-FVC } & =\text { right ventricle fractional volume change } \\ \text { RV-V } & =\text { right ventricle volume }\end{array}$

and dynamics of the tricuspid valve remains incomplete. Early studies in intact dogs demonstrated the "sphincteric" role of the tricuspid annulus (TA) in facilitating valve closure by reducing annular area in biphasic fashion. ${ }^{5}$ Clinically, normal tricuspid annular shape and motion have been investigated using echocardiography $^{6-8}$ with demonstrated TA circumference and area reduction during the cardiac cycle of up to $20 \%$ and $30 \%{ }^{6,9}$ These studies have also revealed the TA to have a complex saddle-shaped geometry ${ }^{9}$ confirmed by recent ovine experiments using implanted sonomicrometry crystals. ${ }^{10-12}$ However, these animal studies were performed in open-chest, mechanically ventilated animals under general anesthesia. The depressive cardiovascular effects of inhalational agents have been well characterized, ${ }^{13-17}$ and it is known that general anesthesia can alter preload, afterload, or right ventricular function, ${ }^{18,19}$ which may in turn affect accurate echocardiographic assessment of tricuspid insufficiency ${ }^{2}$ or valvular dynamics. Currently, no experimental studies in the published literature exist describing precise tricuspid valvular dynamics in awake, ambulatory animals or the potential effect of general anesthesia and mechanical ventilation on these dynamics. Using sonomicrometry crystals, we set out to characterize 3D geometry and dynamics of the tricuspid valvular complex in awake and anesthetized sheep.

\section{MATERIALS AND METHODS}

All animals received humane care in compliance with the Principles of Laboratory Animal Care formulated by the National Society for Medical Research and the Guide for Care and Use of Laboratory Animals prepared by the National Academy of Science and published by the National Institutes of Health. The study was approved by the local Institutional Animal Care and Use Committee.

The study was designed for 12 adult castrated Q-fever negative Dorset male sheep. Six sheep $(50 \pm 8 \mathrm{~kg})$ underwent a successful procedure and completed the study protocol. Four animals died during the recovery period, and 2 others were excluded because of damage to sonomicrometry crystal wires and lack of data acquisition.

\section{Operative Procedure}

During acclimation, a health screening transthoracic echocardiogram was performed to evaluate each animal for any preexisting conditions that may exclude the animal from the study. Before the surgical procedure, the animals were premedicated with ketamine ( $25 \mathrm{mg} / \mathrm{kg}$ intramuscularly) and an intravenous catheter was placed into the left external jugular vein (BD Angiocath, Franklin Lakes, NJ). Sheep were anesthetized with propofol (2-5 mg/kg intravenously [IV]), intubated, and mechanically ventilated. Atropine $(0.1 \mathrm{mg} / \mathrm{kg} \mathrm{IV})$ was given as needed for bradycardia (heart rate $<60$ beats/min). General anesthesia was maintained with isoflurane $(1 \%-2.5 \%)$, and fentanyl $(5-20 \mu \mathrm{g} / \mathrm{kg} / \mathrm{min})$ was infused for analgesia. An $18 \mathrm{Ga}$ arterial catheter (Teleflex Arrow, Morrisville, NC) was introduced through the left carotid artery for arterial blood pressure measurements and blood gas analysis. Muscle paralysis was achieved using vecuronium $(0.1 \mathrm{mg} / \mathrm{kg}$ IV). The operative procedure was performed via a right lateral thoracotomy through the fourth intercostal space while the right neck was exposed for cardiopulmonary bypass cannulation. After obtaining adequate surgical exposure, the animals were fully heparinized (300 IU/kg IV) and the right carotid artery was cannulated using a $14 \mathrm{~F}$ (Medtronic EOPA, Minneapolis, Minn) cannula. By using the Seldinger technique, the right jugular vein was cannulated with a 25F Medtronic venous cannula (Medtronic Bio-Medicus, Minneapolis, Minn), which was advanced to the inferior vena cava, thus permitting isolation of the right atrium. After activated clotting time exceeded 480 seconds, normothermic cardiopulmonary bypass was initiated, both venae cavae were snared, and the right atrium was opened. With the heart beating, each animal underwent implantation of 14 (2-mm) sonomicrometry crystals (Sonometrics Corporation, London, Ontario, Canada) using 5-0 polypropylene suture. Six crystals were sutured around the TA, with 1 crystal at each commissure, defining 3 separate annular regions: anterior, posterior, and septal. One crystal was sutured on the anterior papillary muscle tip, posterior papillary muscle tip, and septal papillary muscle tip, 4 on the right ventricle (RV) free wall epicardium and 1 on the RV apex. Complete crystal array is shown in Figure 1. Annular crystal electrodes were externalized through the right atriotomy, and papillary muscle crystal wires were externalized through the RV apex. An electrocardiogram (ECG) electrode connected to the sonomicrometry system was sutured to the right ventricular free wall. Pressure transducers (Transonics Endogear Inc, Davis, Calif) were placed through the right and left ventricle (LV) apex and connected to a subcutaneously placed EndogearVR biotelemetry system. Subsequently, the animals were weaned from cardiopulmonary bypass. Sonomicrometry crystals, ECG, and pressure transducer connectors were externalized to subcutaneous buttons. Two chest tubes were advanced through the fifth intercostal space. The thoracotomy incision was approximated in standard fashion, and the intercostal nerves in the region of incision were infiltrated with $0.25 \%$ bupivacaine. The animals were recovered in standard fashion and weaned off the ventilator within 3 hours of surgery and were taken from the safety cage back to the pen when standing up and eating (on average $10 \pm 5$ hours postoperatively). The chest tubes were removed when drainage was less than $20 \mathrm{~mL}$ per hour, usually within 24 hours after thoracotomy. Prophylactic antibiotics (cefazolin $2 \mathrm{~g}$ IV every 12 hours, gentamicin $240 \mathrm{mg}$ IV every 24 hours) were given for 7 days postoperatively, beginning with preoperative doses. Buprenorphine $(0.005-0.01 \mathrm{mg} / \mathrm{kg} \mathrm{IV})$ was given for pain as needed, every 5 to 7 hours. An additional dose of dilaudid $(0.03 \mathrm{mg} / \mathrm{kg})$ was given if analgesia from buprenorphine was not sufficient. Carprofen (2-4 mg/kg IV) was used for all 7 days postoperatively to minimize the inflammation and prevent pain.

\section{Data Acquisition}

After 7 days of recovery, the sonomicrometry data acquisition unit was connected to the subcutaneous buttons with the animals awake and standing in the pen. Simultaneous transthoracic echocardiography, hemodynamic, and sonomicrometry data were recorded without administration of any additional medications. Subsequently, the animals were 

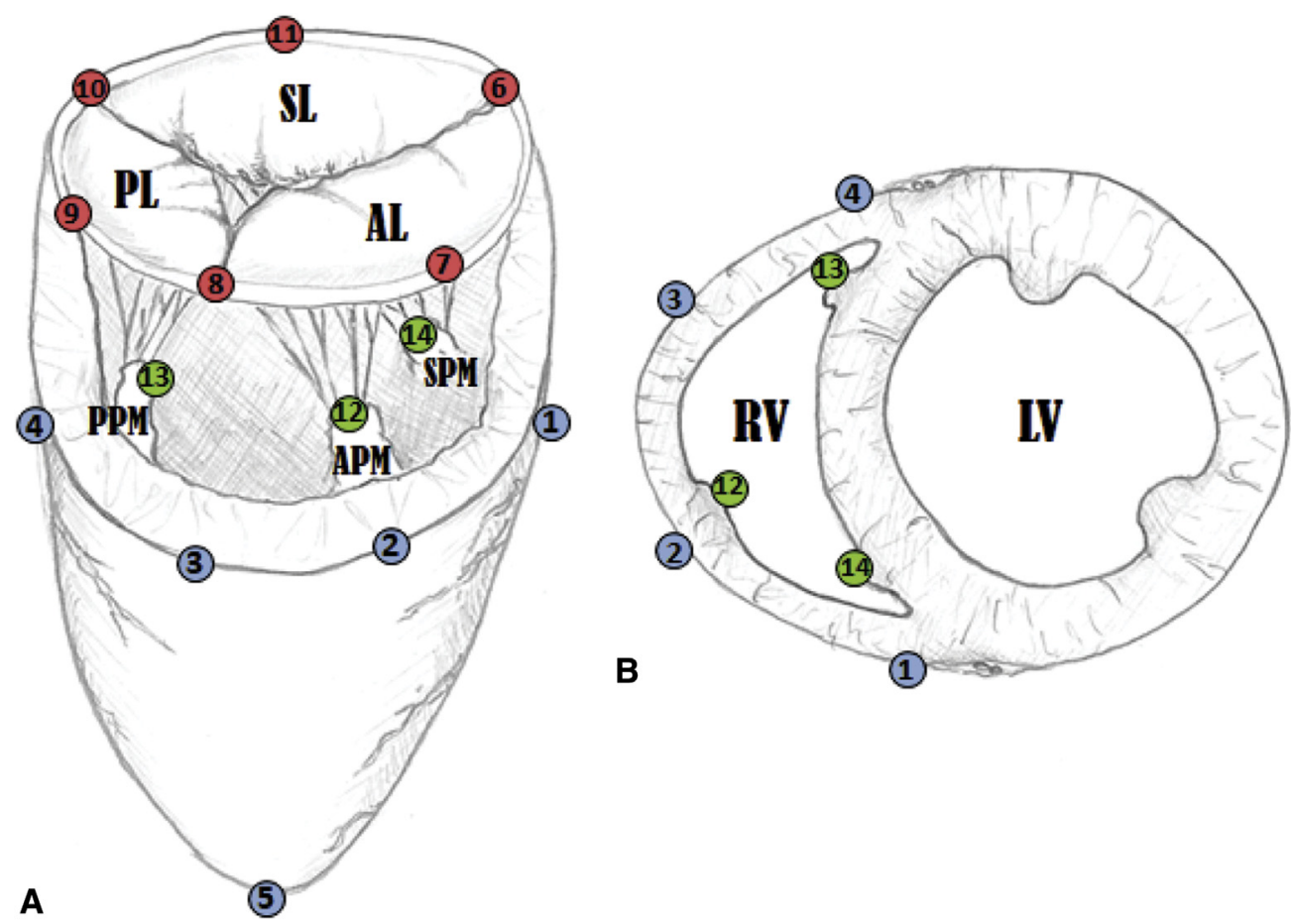

FIGURE 1. The sheep heart with crystal array (1-14). A, RV with tricuspid valve complex. B, Cross-sectional view of RV and LV at the level of RV papillary muscles. $S L$, Septal leaflet; $P L$, posterior leaflet; $A L$, anterior leaflet; $S P M$, septal papillary muscle; $P P M$, posterior papillary muscle; $A P M$, anterior papillary muscle; $R V$, right ventricle; $L V$, left ventricle.

premedicated with propofol (2-5 mg/kg IV), intubated, and mechanically ventilated. Anesthesia was maintained with $1 \%$ to $2 \%$ isoflurane. After 30 minutes of stabilization, simultaneous, echocardiographic, hemodynamic, and sonomicrometry data collection was repeated.

\section{Data Analysis}

All sonomicrometry data were acquired using Sonometrics 32-channel Digital Ultrasonic Measurement System DS3 (Sonometrics Corporation, London, Ontario, Canada) as previously described. ${ }^{20,21}$ Data from 10 consecutive cardiac cycles during sinus rhythm were averaged for each animal. Data were acquired at $128 \mathrm{~Hz}$ with simultaneous LV, RV pressure, and ECG recordings.

TA area, perimeter, and septolateral and anteroposterior annular diameters were calculated from 3D crystal coordinates. Tricuspid annular height was defined as the distance between the 2 maximally displaced crystals above and below the TA plane. The distance from each papillary muscle tip to annular plane and interpapillary muscle area (area circumscribed by crystals 12,13 , and 14) was used to represent subvalvular geometry. The RV cross-sectional area was defined as the area circumscribed by crystals 1, 2, 3, 4, 13, and 14 (Figure 1 and Video 1). The RV volume (RV-V) was calculated using the convex hull method based on annular and epicardial crystal coordinates. Tricuspid annular area was calculated without assumption of planar geometry using an annular centroid, and annular perimeter was calculated as the sum of individual annular segment lengths. ${ }^{20}$ Regional annular length was calculated on the basis of corresponding crystal coordinates: anterior (crystals 6-7-8), posterior (crystals 8-9-10), and septal (crystals 10-11-6). Septal-lateral annular diameter was defined as the distance between crystals 8 and 11, and anteriorposterior diameter was defined as the distance from crystal 7 to crystal 9 . All parameters were calculated at their maximal and minimal values during the cardiac cycle and at end-systole (ES) and end-diastole (ED). ED was defined as a point of positive deflection beginning in ECG voltage ( $R$ wave), and ES was determined as a time of minimal RV-V.
Regional TA perimeter and RV free wall contraction were calculated as the differences between the maximal and minimal distances throughout the cardiac cycle $[(\operatorname{Dmax}-\mathrm{Dmin}) / \mathrm{Dmax} \times 100 \%$ ] for the particular region of TA (anterior, posterior, and septal) and RV free wall 3 segments: anterior (crystals 1-2), lateral (crystals 2-3), and posterior (crystals 3-4) (Figure 1). To determine TA area contraction, RV fractional area change (RV-FAC), and RV fractional volume change (RV-FVC), similar measurements were done.

The degree of valvular insufficiency was assessed using American Society of Echocardiography criteria. Grading included comprehensive evaluation of color flow and continuous-wave Doppler. TR was graded accordingly and categorized by an experienced cardiologist as none or

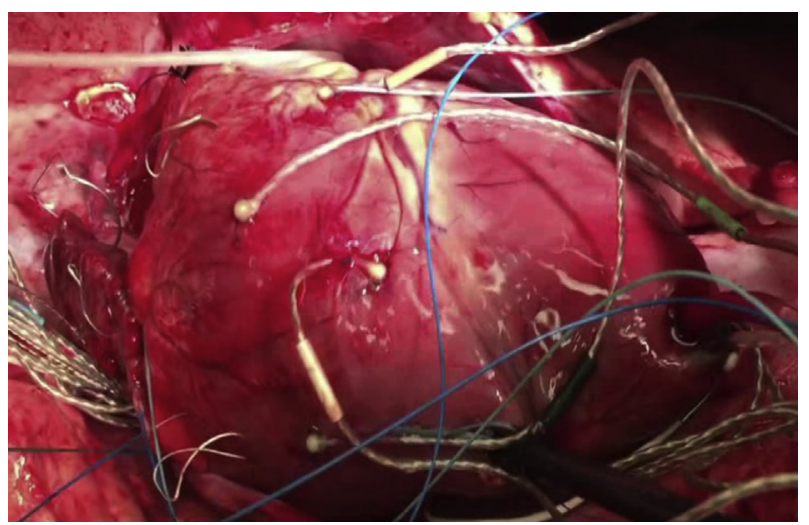

VIDEO 1. Intraoperative view of implanted sonomicrometry crystals. Video available at: https://www.jtcvs.org/article/S0022-5223(18)31052-3/ fulltext. 
trace $(0)$, mild $(+1)$, moderate $(+2)$, moderate to severe $(+3)$, and severe $(+4)$.

\section{Statistical Methods}

All data are presented as mean \pm standard deviation. The measured variables were compared between control (awake) and study group (anesthetized) conditions using the Student 2-tailed $t$ test for dependent observations or the Wilcoxon signed-rank test.

\section{RESULTS}

\section{Hemodynamics}

Heart rate did not differ between groups (awake $116 \pm 17$ vs anesthetized $115 \pm 13$ beats $/ \mathrm{min}, P=.932$ ). Moreover, the maximal LV pressure $(110 \pm 9$ vs $106 \pm 27 \mathrm{~mm} \mathrm{Hg}$, $P=.207)$, maximal $\mathrm{RV}$ pressure ( $36 \pm 11$ vs $34 \pm 4 \mathrm{~mm}$ $\mathrm{Hg}, P=.784)$, and minimal $\mathrm{RV}$ pressure $(11.2 \pm 9.3 \mathrm{vs}$ $8.1 \pm 7.5 \mathrm{~mm} \mathrm{Hg}, P=.246)$ remained unchanged under general anesthesia.

\section{Tricuspid Annular Geometry}

Figure 2 illustrates the 3D shape of TA at ED in the awake animals. Two-dimensional projection of the annular area for both groups is displayed in Figure 3, with associated area change from maximum to minimum during the cardiac cycle. Displacement of individual crystals from the annular plane appeared unaffected by anesthesia and mechanical ventilation at ES or ED (Figure 4). Tricuspid annular height was similar, being $3.9 \pm 1.0 \mathrm{~mm}$ and $4.2 \pm 1.2 \mathrm{~mm}$ for awake and anesthetized animals, respectively $(P=.357)$.

Variables representing tricuspid annular geometry and dynamics are shown in Table 1. Tricuspid annular area contraction during the cardiac cycle decreased significantly from $16.4 \% \pm 4.2 \%$ to $11.2 \% \pm 3.2 \%(P=.047)$, with anesthesia as illustrated in Figure 3. Likewise, TA perimeter contraction decreased under general anesthesia from $8.1 \% \pm 2.2 \%$ to $5.4 \% \pm 1.8 \%(P=.050)$, mostly due to reduced contraction of the septal annulus. Septolateral and anteroposterior diameter lengths did not change with general anesthesia; however, contraction of S-L diameter decreased significantly.

In awake and anesthetized sheep, TA reached its maximum area directly before atrial depolarization, and TA area contraction was biphasic, with contraction during both atrial and ventricular systole. A representative sample of simultaneous hemodynamic, ECG, annular area, and $\mathrm{RV}-\mathrm{V}$ recordings of a single animal awake and under general anesthesia is shown in Figure 5.

\section{Subvalvular and Right Ventricle Geometry}

Minimal distance from anterior, posterior, and septal papillary muscle tips to the annular plane did not change with anesthesia. Likewise, minimal interpapillary muscle area did not differ between groups (Table 2).

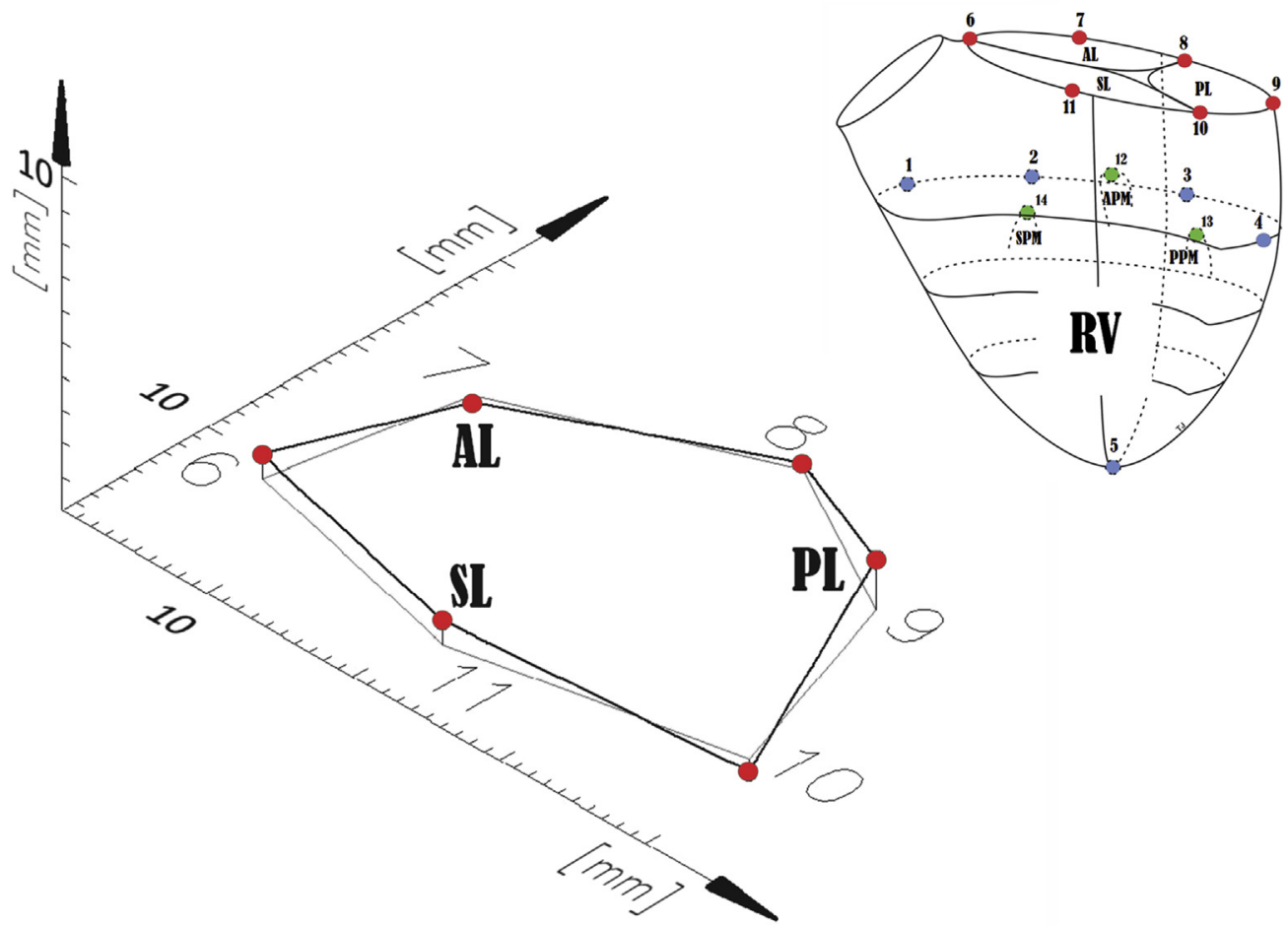

FIGURE 2. The 3D tricuspid annular geometry of awake animals $(\mathrm{N}=6)$ at $\mathrm{ED}$. The thick line with red spheres represents the annulus, and the thin line refers to annular plane. The numbers (6-11) show the location of the consecutive annular crystals as visualized on the RV scheme in the right upper corner of the figure; (6-7-8): anterior annulus; (8-9-10): posterior annulus; (10-11-6): septal annulus. $A L$, Anterior leaflet; $S L$, septal leaflet; $P L$, posterior leaflet; $A P M$, anterior papillary muscle; $S P M$, septal papillary muscle; $P P M$, posterior papillary muscle; $R V$, right ventricle. 

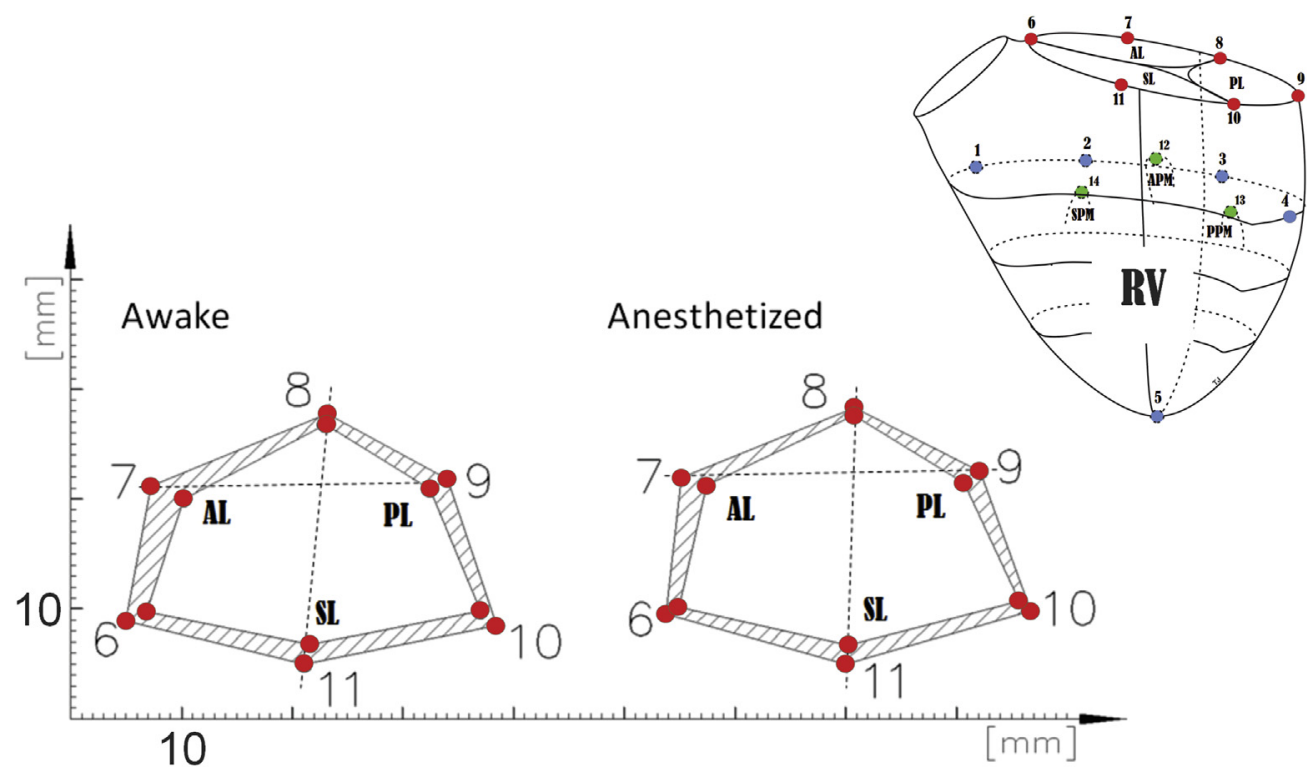

FIGURE 3. The 2-dimensional view of tricuspid annular area change in awake and anesthetized animals. Maximal and minimal tricuspid annular areas are visualized, with shaded field representing the area change during contraction. The numbers (6-11) show the location of the consecutive annular crystals as visualized on the RV scheme in the right upper corner of the figure; (6-7-8): anterior annulus; (8-9-10): posterior annulus; (10-11-6): septal annulus. Dashed lines represent septolateral diameter (8-11) and anteroposterior diameter (7-9). $A L$, Anterior leaflet; $S L$, septal leaflet; $P L$, posterior leaflet; $A P M$, anterior papillary muscle; $S P M$, septal papillary muscle; $P P M$, posterior papillary muscle; $R V$, right ventricle.

Minimal RV cross-sectional area and sonomicrometryderived RV-V were greater under general anesthesia, which caused a decrease of RV-FAC and RV-FVC, respectively, in that group (Table 2).

Regional RV free wall contraction was depressed in 2 segments (crystals 1-2 and 2-3), whereas the third segment (crystals 3-4) remained unchanged under anesthesia (Table 2).

\section{Echocardiography}

Echocardiographic evaluation of the tricuspid valve revealed increased tricuspid regurgitation under general

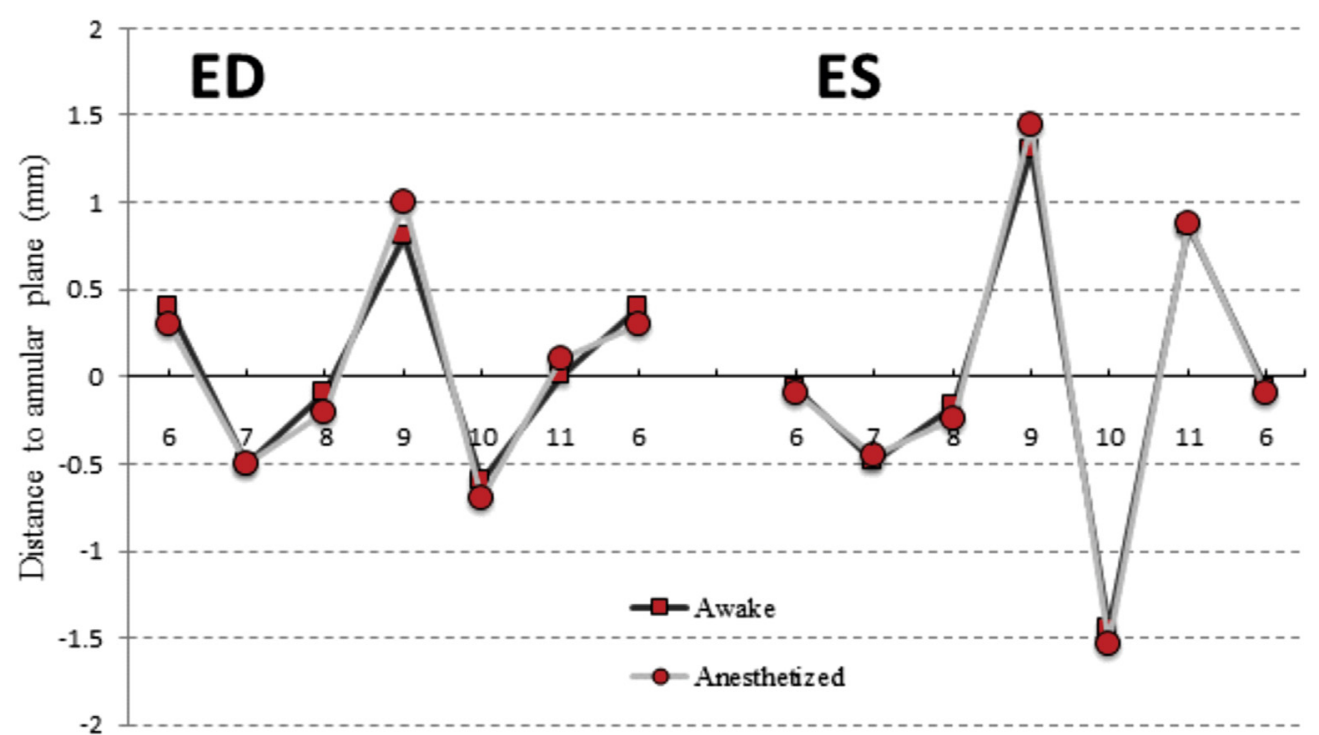

FIGURE 4. Orthogonal displacement of annular markers from the least-squares annular plane at ED and ES in awake and anesthetized animals. The numbers (6-11) show the consecutive annular crystals as visualized in Figure 1; (6-7-8): anterior annulus; (8-9-10): posterior annulus; (10-11-6): septal annulus. $E D$, End-diastole; $E S$, end-systole. 
TABLE 1. Tricuspid annular dynamics and geometry

\begin{tabular}{|c|c|c|c|}
\hline $\mathbf{N}=\mathbf{6}$ & Awake & Anesthetized & $P$ value \\
\hline \multicolumn{4}{|l|}{ TA area } \\
\hline Maximum $\left(\mathrm{mm}^{2}\right)$ & $696 \pm 169$ & $683 \pm 143$ & NS \\
\hline Minimum $\left(\mathrm{mm}^{2}\right)$ & $583.8 \pm 158.0$ & $608.9 \pm 143.1$ & NS \\
\hline $\mathrm{ED}\left(\mathrm{mm}^{2}\right)$ & $638.9 \pm 171.8$ & $649.1 \pm 145.0$ & NS \\
\hline $\mathrm{ES}\left(\mathrm{mm}^{2}\right)$ & $611.8 \pm 145.8$ & $631.7 \pm 142.9$ & NS \\
\hline Contraction $(\%)$ & $16.4 \pm 4.2$ & $11.2 \pm 3.2$ & .047 \\
\hline \multicolumn{4}{|l|}{ TA perimeter $(\mathrm{mm})$} \\
\hline \multicolumn{4}{|l|}{ Total } \\
\hline Maximum (mm) & $101 \pm 12$ & $100 \pm 11$ & NS \\
\hline Minimum (mm) & $92.8 \pm 12.6$ & $94.7 \pm 11.7$ & NS \\
\hline Contraction $(\%)$ & $8.1 \pm 2.2$ & $5.4 \pm 1.8$ & .050 \\
\hline \multicolumn{4}{|l|}{ Anterior (6-7-8) } \\
\hline Maximum (mm) & $29.7 \pm 6.2$ & $29.3 \pm 6.0$ & NS \\
\hline Minimum (mm) & $25.3 \pm 6.3$ & $26.0 \pm 5.6$ & NS \\
\hline Contraction $(\%)$ & $15.6 \pm 4.9$ & $11.5 \pm 2.7$ & NS \\
\hline \multicolumn{4}{|l|}{ Posterior (8-9-10) } \\
\hline Maximum (mm) & $26.4 \pm 5.4$ & $26.2 \pm 5.1$ & NS \\
\hline Minimum (mm) & $23.1 \pm 5.3$ & $23.5 \pm 5.5$ & NS \\
\hline Contraction $(\%)$ & $13.0 \pm 2.6$ & $10.8 \pm 4.4$ & NS \\
\hline \multicolumn{4}{|l|}{ Septal (10-11-6) } \\
\hline Maximum (mm) & $34.3 \pm 6.6$ & $34.3 \pm 6.0$ & NS \\
\hline Minimum (mm) & $30.7 \pm 6.1$ & $31.7 \pm 5.4$ & NS \\
\hline Contraction (\%) & $10.5 \pm 2.9$ & $7.5 \pm 3.5$ & .019 \\
\hline \multicolumn{4}{|l|}{ TA dimensions } \\
\hline \multicolumn{4}{|l|}{ Septolateral (8-11) } \\
\hline Maximum (mm) & $27.4 \pm 3.6$ & $27.3 \pm 3.6$ & NS \\
\hline Minimum (mm) & $23.4 \pm 2.9$ & $23.8 \pm 3.1$ & NS \\
\hline Contraction $(\%)$ & $14.5 \pm 3.8$ & $12.8 \pm 3.6$ & .046 \\
\hline \multicolumn{4}{|l|}{ Anteroposterior (7-9) } \\
\hline Maximum (mm) & $28.4 \pm 6.3$ & $28.8 \pm 6.2$ & NS \\
\hline Minimum (mm) & $24.4 \pm 6.3$ & $25.4 \pm 6.3$ & NS \\
\hline Contraction $(\%)$ & 13.9 & 11.6 & NS \\
\hline
\end{tabular}

Values are means \pm standard deviation; $\mathrm{N}$ : number of subjects. The numbers (1-9) represent the consecutive annular crystals as shown in Figure 1. TA, Tricuspid annulus; $N S$, not significant; $E D$, end-diastole; $E S$, end-systole.

anesthesia (awake: $0.3 \pm 0.5$ vs anesthetized: $1.16 \pm 0.4$; $P=.043)$.

\section{DISCUSSION}

The current study is the first to report precise 3D geometry and dynamic motion of the tricuspid valve in awake, ambulatory sheep. General anesthesia reduced dynamic motion of the TA and RV function, but annular and subvalvular geometry remained unchanged. The 3D geometry of the annulus reconstructed in our study was that of a saddle-shaped structure with 2 peaks (horns), 1 located near the anteroseptal commissure and 1 located in the posterior section of annulus. Neither the shape nor the height of the TA appeared to be altered by general anesthesia. These data corroborate our previous findings of ovine TA 3D structure and geometry in acute experiments. ${ }^{20,21}$ Other investigators have reported comparable results. ${ }^{10,11}$ However, these studies were performed in open-chest anesthetized animals in the acute setting. Similar bimodal shape of the TA was observed with 3D echocardiography in human subjects. ${ }^{22}$ The presence of a "saddle" geometry also has been reported for the mitral annulus, ${ }^{23}$ and preservation of such geometry may permit optimal leaflet stress distribution particularly on the anterior mitral leaflet. ${ }^{24}$ Whether conservation of this shape in the TA has a similar effect on the tricuspid valve leaflets remains to be established.

In the current study, a biphasic tricuspid annular contraction was observed with annular area reduction both during atrial and ventricular systole. Similar annular dynamics were reported by Tsakiris and colleagues ${ }^{5}$ in anesthetized dogs. The pattern of biphasic annular reduction in our study was also maintained under anesthesia. The ability of the TA to contract in a "sphincteric" fashion has been described as crucial for maintaining tricuspid valve competency. ${ }^{5}$ In the present study, TA area contraction in awake animals was $16.4 \%$ and decreased to $11.2 \%$ under anesthesia. This was a meaningful reduction, although with borderline statistical significance. In prior studies of healthy anesthetized open-chest, open pericardium sheep, we reported an annular area reduction of $18 \% .{ }^{20}$ A value of $21.9 \%$ was reported by Hiro and colleagues ${ }^{11}$ in a similar ovine model. The differences among the observed TA area reduction in these anesthetized animal studies may be partially explained by higher heart rate in our study, because higher heart rate was associated with decreased TA area contraction in anesthetized dogs. ${ }^{5}$ Depth of anesthesia and analgesia may have contributed further.

TA area reduction is related to annular perimeter shortening. In our study, perimeter contraction changed under general anesthesia, decreasing from $8.1 \%$ to $5.4 \%$; however, the statistical significance was marginal. The septal annular region has been found to be least involved in annular perimeter contraction, ${ }^{10,20,21}$ but its contraction was most affected by anesthesia in our study. Indeed, it was the only portion of the annulus that significantly diminished its contraction. These findings suggest an important role of the ventricular septum in mediating annular dynamics. Recent high-definition transesophageal echocardiography-based reconstruction of human tricuspid valves revealed similar heterogeneity of regional tricuspid annular contraction. ${ }^{25}$ In our study, anterior annulus contraction did not change after anesthesia even though the underlying RV free wall segments were significantly affected. It has been shown that much of the anterior annulus originates from the supraventricular crest, which does not arise from the free wall. ${ }^{26}$ Supraventricular crest acts as an adductor muscle connecting the RV with interventricular septum. These anatomic features suggest that the changes in anterior annulus reduction may not directly reflect anterior RV wall contraction (Crystals 1-2 and 2-3). The posterior annulus, which originates 


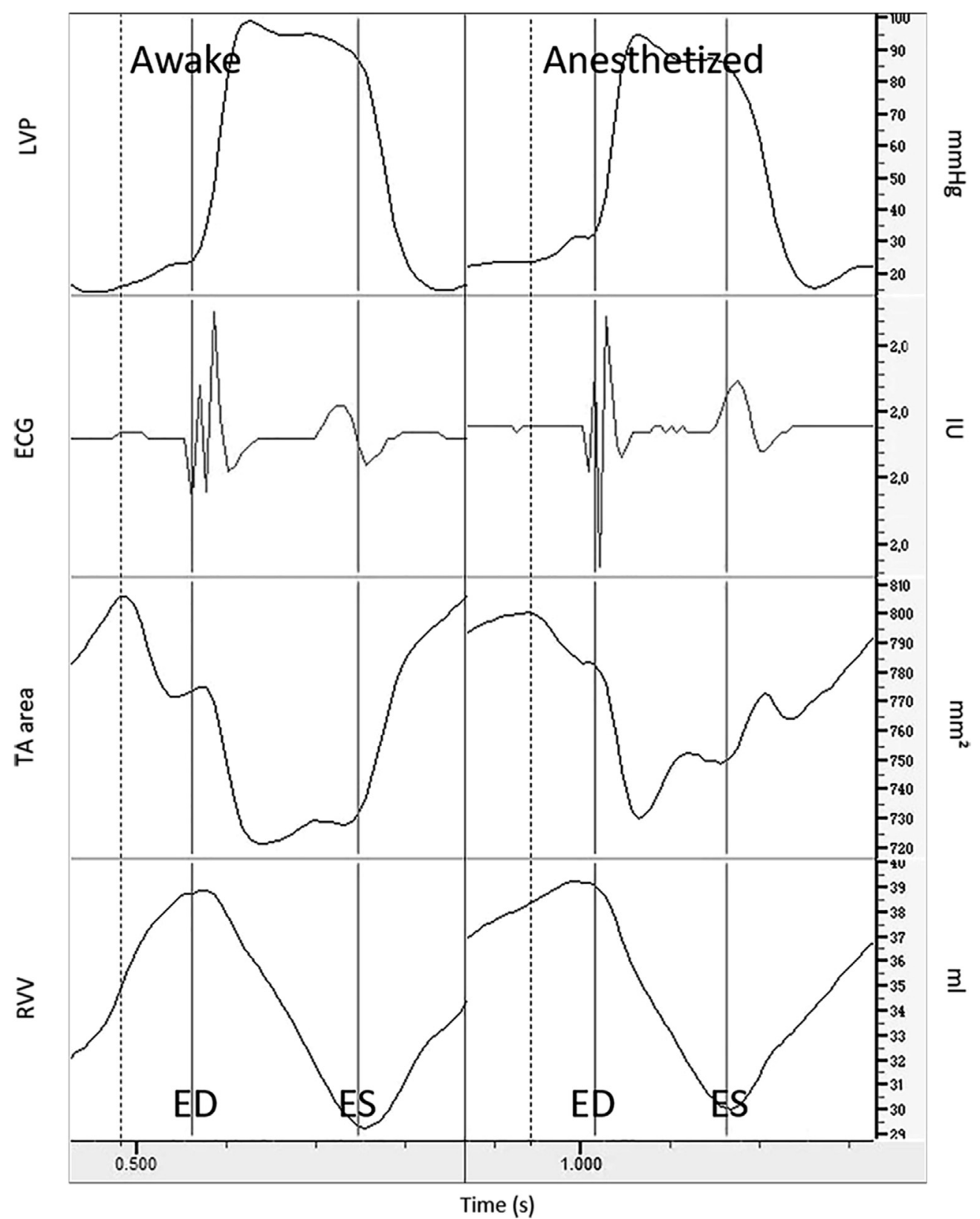

FIGURE 5. The dynamic changes of the tricuspid annular area during the cardiac cycle in 1 representative animal. Dashed line indicates maximal tricuspid area directly before atrial depolarization. $L V P$, Left ventricle pressure; $E C G$, electrocardiogram; $T A$, tricuspid annulus; $R V V$, right ventricle volume; $E D$, enddiastole; $E S$, end-systole.

from the posterior RV wall, maintained dynamic changes that closely tracked the posterior RV free wall (Crystals 3-4).

We assume that the previously described ability of TA to fold $^{26,27}$ may contribute to TA area contraction. In our study, septal-lateral diameter contraction was reduced by general anesthesia, whereas anterior-posterior diameter contraction remained unchanged. We speculate that the RV free wall might participate in the TA folding phenomenon because the anterior RV free wall showed decreased contractility after anesthesia.
Isoflurane-based general anesthesia has been shown to decrease arterial blood pressure, cardiac output, stroke volume, and LV and RV contraction. ${ }^{13,14,17,19}$ In addition, it decreases preload by direct venous dilation. ${ }^{18}$ Thus, decreased annular area reduction during anesthesia may be mediated by direct myocardial depression and altered hemodynamic milieu. Mechanical ventilation with positive end-expiratory pressure (PEEP) has a preload reducing effect on the $\mathrm{RV},{ }^{28}$ and PEEP may also increase RV afterload and decrease RV contractility in a range-dependent fashion. ${ }^{28}$ In our study, PEEP was maintained at $5 \mathrm{~mm} \mathrm{Hg}$ 
TABLE 2. Subvalvular and right ventricle geometry

\begin{tabular}{|c|c|c|c|}
\hline $\mathbf{N}=\mathbf{6}$ & Awake & Anesthetized & $P$ value \\
\hline \multicolumn{4}{|l|}{ Subvalvular geometry } \\
\hline $\mathrm{APM}^{-\mathrm{TAP}}$ min distance $(\mathrm{mm})$ & $19.3 \pm 2.5$ & $20.4 \pm 3.5$ & NS \\
\hline $\mathrm{PPM} \mathrm{TAP}_{\text {min }}$ distance $(\mathrm{mm})$ & $17.1 \pm 3.0$ & $18.2 \pm 3.4$ & NS \\
\hline $\mathrm{SPM} \mathrm{TAP}_{\text {min }}$ distance $(\mathrm{mm})$ & $19.3 \pm 3.3$ & $20.0 \pm 3.3$ & NS \\
\hline Inter-PM ${ }_{\min }$ area $\left(\mathrm{mm}^{2}\right)$ & $139.1 \pm 66.3$ & $152.5 \pm 88.9$ & NS \\
\hline \multicolumn{4}{|l|}{ RV geometry and function } \\
\hline $\mathrm{RV}^{-C S A} \mathrm{max}_{\max }\left(\mathrm{mm}^{2}\right)$ & $1385.4 \pm 240.7$ & $1400.3 \pm 149.8$ & NS \\
\hline $\mathrm{RV}-\mathrm{CSA} \min _{\min }\left(\mathrm{mm}^{2}\right)$ & $957.0 \pm 229.6$ & $1037.1 \pm 198.7$ & .020 \\
\hline RV-FAC (\%) & $31.6 \pm 7.7$ & $26.6 \pm 6.9$ & .041 \\
\hline $\mathrm{RV}-\mathrm{V}_{\text {max }}(\mathrm{mL})$ & $49.9 \pm 11.3$ & $50.2 \pm 11.0$ & NS \\
\hline $\mathrm{RV}-\mathrm{V}_{\min }(\mathrm{mL})$ & $35.1 \pm 6.6$ & $38.4 \pm 9.0$ & .046 \\
\hline RV-FVC (\%) & $29.0 \pm 4.4$ & $23.6 \pm 3.3$ & .027 \\
\hline \multicolumn{4}{|l|}{ RV free wall contraction } \\
\hline Anterior (1-2) (\%) & $16.3 \pm 3.1$ & $12.3 \pm 2.2$ & .027 \\
\hline Lateral $(2-3)(\%)$ & $14.9 \pm 1.3$ & $11.5 \pm 2.8$ & .016 \\
\hline Posterior (3-4) (\%) & $10.2 \pm 2.7$ & $8.7 \pm 2.6$ & NS \\
\hline
\end{tabular}

Values are means \pm standard deviation; N: number of subjects. The numbers (1-4) represent the consecutive RV free wall crystals as shown in Figure 1. APM, Anterior papillary muscle; $T A P$, tricuspid annular plane; $\min$, minimal; $N S$, not significant; $P P M$, posterior papillary muscle; $S P M$, septal papillary muscle; $P M$, papillary muscle; $R V$ - $C S A$, RV crosssectional area; $R V$ - $F A C$, RV fractional area change; $R V-V$, RV volume; max, maximal; $R V-F V C$, RV fractional volume change; $R V$, right ventricle.

throughout anesthesia, which may favor a preload reducing effect. Nonetheless, according to the study of Couture and colleagues,${ }^{18}$ it is possible that the influence of mechanical ventilation in our study might represent a balance between an increase in RV afterload and a reduction of RV preload. ${ }^{18}$ In contrast, Murray and colleagues ${ }^{29}$ suggest that because of the normal ongoing volume loss replacement during anesthesia, decrease in stroke volume depends more on myocardial depression rather than reduced RV preload. Maximal RV-V did not change under anesthesia in our study, whereas both RV-FAC and RV-FVC decreased significantly. Furthermore, regional RV free wall contraction was depressed in 2 segments. These data lend support to previously published findings. ${ }^{19,29}$

Clinical echocardiographic studies of the mitral valve have demonstrated that general anesthesia may significantly influence functional valvular insufficiency. ${ }^{30-32}$ Because of reduced preload, filling of the $\mathrm{LV}$ in functional mitral regurgitation is reduced, resulting in less leaflet tethering and improved coaptation observed on transesophageal echocardiography. ${ }^{30-32}$ Similar mechanisms may be assumed to influence the tricuspid valvular complex under general anesthesia. Dreyfus and colleagues ${ }^{2}$ proposed that in nonanesthetized patients with mild TR and annular diameter of more than $40 \mathrm{~mm}$, any additional changes in preload, afterload, or right ventricular function may lead to increased valvular insufficiency. General anesthesia is known to influence these hemodynamic variables; therefore, it is reasonable to conjecture that anesthesia and mechanical ventilation might be important modulators of tricuspid valve regurgitation.

However, tricuspid valve leaflet coaptation is perhaps more complex because of the presence of 3 leaflets and the influence of the interventricular septum. The septal leaflet, whose papillary muscle is attached to the ventricular septum, is affected by a right to left septal shift, ${ }^{2}$ which may decrease coaptation. This mechanism has been described in acute LV unloading conditions mimicking reduced LV preload. ${ }^{33}$ Theoretically, reduced LV preload during anesthesia may increase septal leaflet tethering through displacement of the septum, but in the current study, we found no effect of general anesthesia on papillary muscle position. Neither maximal RV-V nor RV cross-sectional area changed during general anesthesia, although minimal $\mathrm{RV}$ cross-sectional area and volume increased significantly. This systolic increase in chamber size did not affect subvalvular geometry. Nonetheless, these were normal sheep hearts, and no intervention was undertaken to induce clinically significant RV dilation through pressure or volume overload. We did find increased degree for tricuspid insufficiency under general anesthesia, although the severity of insufficiency was still only mild. Whether this finding was due to better acoustic windows in an anesthetized animal or a real physiologic phenomenon is difficult to discern.

Clinically, intraoperative assessment of the tricuspid valve with transesophageal echocardiography during cardiac surgery warrants consideration of these data. Although 3D annular geometry remains stable under anesthesia, annular contraction may be altered. Therefore, the balance between reduced RV preload and annular contraction may be the determinant of valvular competence, and this equilibrium deserves close attention during clinical imaging. However, any further clinical extrapolation would require a chronic model of RV dysfunction and functional tricuspid regurgitation. 


\section{Study Limitations}

The results of our study must be interpreted in the context of important limitations. The experimental group was small, and larger confirmatory studies are needed. However, the paired design of the study gives us confidence in its results. In addition, this study did not investigate leaflet dynamics that may also be affected by general anesthesia. Only healthy animals were included in the experiment, and as such, extrapolation of results into clinical practice should be performed with caution.

\section{CONCLUSIONS}

Our study of healthy adult sheep describes in detail the dynamic motion and complex geometry of the tricuspid valve in awake, ambulatory animals. General anesthesia and mechanical ventilation reduced annular dynamics and right ventricular contractility, but annular and subvalvular geometry remained unaffected. These data provide unique insight into normal tricuspid valve shape and motion and provide context for interpretation of tricuspid dynamics and geometry under general anesthesia during intraoperative decision making and perioperative care.

\section{Conflict of Interest Statement}

T.J. and M.M. are the Peter C. and Pat Cook Endowed Research Fellows in Cardiothoracic Surgery. All other authors have nothing to disclose with regard to commercial support.

\section{References}

1. Bruce CJ, Connolly HM. Right-sided valve disease deserves a little more respect. Circulation. 2009;119:2726-34.

2. Dreyfus GD, Martin RP, Chan KM, Dulguerov F, Alexandrescu C. Functional tricuspid regurgitation: a need to revise our understanding. J Am Coll Cardiol. 2015;65:2331-6.

3. Pfannmuller B, Doenst T, Eberhardt K, Seeburger J, Borger MA, Mohr FW. Increased risk of dehiscence after tricuspid valve repair with rigid annuloplasty rings. J Thorac Cardiovasc Surg. 2012;143:1050-5.

4. McCarthy PM, Bhudia SK, Rajeswaran J, Hoercher J, Lytle BW, Cosgrove DM, et al. Tricuspid valve repair: durability and risk factors for failure. J Thorac Cardiovasc Surg. 2004;127:674-85.

5. Tsakiris AG, Mair DD, Seki S, Titus JL, Wood EH. Motion of the tricuspid valve annulus in anesthetized intact dogs. Circ Res. 1975;36:43-8.

6. Tei C, Pilgrim JP, Shah PM, Ormiston JA, Wong M. The tricuspid valve annulus: study of size and motion in normal subjects and in patients with tricuspid regurgitation. Circulation. 1982;66:665-71.

7. Anwar AM, Geleijnse ML, Ten Cate FJ, Meijboom FJ. Assessment of tricuspid valve annulus size, shape and function using real-time three-dimensional echocardiography. Interact Cardiovasc Thorac Surg. 2006;5:683-7.

8. Ring L, Rana BS, Kydd A, Boyd J, Parker K, Rusk RA. Dynamics of the tricuspid valve annulus in normal and dilated right hearts: a three-dimensional transoesophageal echocardiography study. Eur Heart J Cardiovasc Imaging. 2012;13:756-62.

9. Fukuda S, Gillinov AM, Song JM, Daimon M, Kongsaerepong V, Thomas JD, et al. Echocardiographic insights into atrial and ventricular mechanisms of functional tricuspid regurgitation. Am Heart J. 2006;152:1208-14.

10. Fawzy H, Fukamachi K, Mazer CD, Harrington A, Latter D, Bonneau D, et al. Complete mapping of the tricuspid valve apparatus using three-dimensional sonomicrometry. J Thorac Cardiovasc Surg. 2011;141:1037-43.

11. Hiro ME, Jouan J, Pagel MR, Lansac E, Lim KH, Lim HS, et al. Sonometric study of the normal tricuspid valve annulus in sheep. J Heart Valve Dis. 2004;13: 452-60.
12. Jouan J, Pagel MR, Hiro ME, Lim KH, Lansac E, Duran CM. Further information from a sonometric study of the normal tricuspid valve annulus in sheep: geometric changes during the cardiac cycle. J Heart Valve Dis. 2007;16:511-8.

13. Klide AM. Cardiopulmonary effects of enflurane and isoflurane in the dog. Am J Vet Res. 1976;37:127-31.

14. Steffey EP, Howland D Jr. Isoflurane potency in the dog and cat. Am J Vet Res. 1977;38:1833-6.

15. Pagel PS, Kampine JP, Schmeling WT, Warltier DC. Comparison of the systemic and coronary hemodynamic actions of desflurane, isoflurane, halothane, and enflurane in the chronically instrumented dog. Anesthesiology. 1991;74:539-51.

16. Deryck YL, Brimioulle S, Maggiorini M, de Canniere D, Naeije R. Systemic vascular effects of isoflurane versus propofol anesthesia in dogs. Anesth Analg. 1996;83:958-64.

17. Sousa MG, Carareto R, De-Nardi AB, Brito FL, Nunes N, Camacho AA. Effects of isoflurane on echocardiographic parameters in healthy dogs. Vet Anaesthes Analg. 2008;35:185-90.

18. Couture P, Denault AY, Shi Y, Deschamps A, Cossette M, Pellerin M, et al. Ef fects of anesthetic induction in patients with diastolic dysfunction. Can J Anaesthes. 2009;56:357-65.

19. Priebe HJ. Differential effects of isoflurane on regional right and left ventricular performances, and on coronary, systemic, and pulmonary hemodynamics in the dog. Anesthesiology. 1987;66:262-72.

20. Malinowski M, Wilton P, Khaghani A, Langholz D, Hooker V, Eberhart L, et al. The effect of pulmonary hypertension on ovine tricuspid annular dynamics. Eur J Cardiothorac Surg. 2016:49:40-5.

21. Malinowski M, Wilton P, Khaghani A, Brown M, Langholz D, Hooker V et al. The effect of acute mechanical left ventricular unloading on ovine tricuspid annular size and geometry. Interact Cardiovasc Thorac Surg. 2016;23:391-6.

22. Ton-Nu TT, Levine RA, Handschumacher MD, Dorer DJ, Yosefy C, Fan D, et al Geometric determinants of functional tricuspid regurgitation: insights from 3-dimensional echocardiography. Circulation. 2006;114:143-9.

23. Gorman JH III, Gupta KB, Streicher JT, Gorman RC, Jackson BM, Ratcliffe MB et al. Dynamic three-dimensional imaging of the mitral valve and left ventricle by rapid sonomicrometry array localization. J Thorac Cardiovasc Surg. 1996;112: 712-26.

24. Amini R, Eckert CE, Koomalsingh K, McGarvey J, Minakawa M, Gorman JH, et al On the in vivo deformation of the mitral valve anterior leaflet: effects of annular geometry and referential configuration. Ann Biomed Eng. 2012;40:1455-67.

25. Owais K, Taylor CE, Jiang L, Khabbaz KR, Montealegre-Gallegos M, Matyal R, et al. Tricuspid annulus: a three-dimensional deconstruction and reconstruction. Ann Thorac Surg. 2014;98:1536-42.

26. Kawada N, Naganuma H, Muramatsu K, Ishibashi-Ueda H, Bando K, Hashimoto K. Redefinition of tricuspid valve structures for successful ring annuloplasty. J Thorac Cardiovasc Surg. 2018;155:1511-9.e1511.

27. Rausch MK, Malinowski M, Wilton P, Khaghani A, Timek TA. Engineering analysis of tricuspid annular dynamics in the beating ovine heart. Ann Biomed Eng. 2018;46:443-51.

28. Biondi JW, Schulman DS, Soufer R, Matthay RA, Hines RL, Kay HR, et al. The effect of incremental positive end-expiratory pressure on right ventricular hemodynamics and ejection fraction. Anesthes Analg. 1988;67:144-51.

29. Murray D, Vandewalker G, Matherne GP, Mahoney LT. Pulsed Doppler and twodimensional echocardiography: comparison of halothane and isoflurane on cardiac function in infants and small children. Anesthesiology. 1987;67:211-7.

30. Bach DS, Deeb GM, Bolling SF. Accuracy of intraoperative transesophageal echocardiography for estimating the severity of functional mitral regurgitation. Am J Cardiol. 1995;76:508-12.

31. Chin JH, Lee EH, Choi DK, Choi IC. The effect of depth of anesthesia on the severity of mitral regurgitation as measured by transesophageal echocardiography. J Cardiothorac Vasc Anesth. 2012;26:994-8.

32. Grewal KS, Malkowski MJ, Piracha AR, Astbury JC, Kramer CM, Dianzumba S et al. Effect of general anesthesia on the severity of mitral regurgitation by transesophageal echocardiography. Am J Cardiol. 2000;85:199-203.

33. Moon MR, Bolger AF, DeAnda A, Komeda M, Daughters GT, Nikolic SD II, et al. Septal function during left ventricular unloading. Circulation. 1997;95: 1320-7.

Key Words: tricuspid valve, valve repair, functional tricuspid regurgitation 